\title{
The Visitors
}

\section{Thomas Doherty}

"Its life is over, but its cling lingers on." Lish tried the line in a letter to his remaining sons, but worried over it, fearing that its meaning would be lost in translation.

Never finished the letter anyway:

Dear

1. Its life is over but its cling lingers on. Reference the vine over the window where I have moved since writing you last.

2. Considerable has transpired in the interim. It is my sad duty to inform you of the fate of your older brother whom you never met and I met only once. Though he is dead his grip on all of us

He let it sit for two weeks in the typewriter, then retrieved the carbon papers and forlornly floated the whites into the wastebasket. His eyes settled again upon a snapshot taped to the desk blotter. It was a yellowed and ragged photo, torn from a magazine. An Oriental boy stands barefoot in ankle deep snow, his muddy mouth and undernourished eyes grinning into the white man's camera. There is snow in his hair. A Lone Ranger tee shirt, torn at both shoulders, is stuffed into oversized combat trousers which are cut off at the knees. Charred hands hang from wrists of knotty bone. Yet in spite of the battles that have taken his parents and his home, and in spite of the cold gas stretching his stomach, his smile reflects a simple good humor and nothing more, as if all he expects and hopes for is a GI's joke.

Lish shuddered and turned away from all the starved, good humored faces on his desk.

Deep in a basement office of the Octagon, on a morning months before. . . .

Lish's eyes cruised blocks of names and numbers. What he saw clearly brought clear responses. With a red pencil he marked a code by each name, and each name so marked meant one job filled, one man's fate settled. A bubble of satisfaction floated up his neck and popped in his head, spreading warmth. He 
cranked the handle, and the scroll advanced, bringing more names. Hand on wheel, fingers on pencil, eyes on scroll-a compassionate machine, weaving the fabric of an army.

The motions of the larger machine, the office, stirred in the corners of his eyes.

One step beyond the forward edge of his desk sat Wendy Grossheart. Her orange head, a ball of yarn over which sharp-clawed birds had walked, was bowed to the handbag in her lap. When the head sprang back it squirted smoke at the ceiling. Oiled fingers carried the cigaret over a plasticene mat cratered with burns. The mat and the blotter beneath it were a battlefield of coffee and ink stains and the fossilized spray of winter sneezes. Her cigaret tinked against the glass notch and slid into the pit. Fingers sprang back to her lap, and handbag crashed to the floor. Chair squeaked. Seeing her eyebrows, Lish saw also fresh jetstreams in a cloudless sky.

"How's your mother?" he asked.

"Ohhhh, she'zzzz ...." As always first thing in the morning her voice was out of control. One syllable would not move off stage for the next, and as she struggled for change, the first syllable ran up and down the scales, showing off.

She grabbed her water glass and, getting the jump on her poor coordination, rushed into the corridor. Her eyes, which he never saw when they were before him, marked his memory as puppy noses mark windows.

(Catala, G. F. Hmmm. Generally low abstraction quota. A dodo, in fact. High warrior strain characteristics, however. Infantry? Aha, irregular legs. Well? . . . Yes, we'll make him a laundry and impregmentation specialist . . . Catalingua, J. A. Hmmm ...)

"Did you hear about the Peeping Toms?" Wendy asked. Her voice was much improved. She set the glass, now wrapped in a brown paper towel, on her desk then lowered herself to her chair.

Lish slowed the scroll, pondering. "The whats?"

"My God, you haven't? Why, several people . . . some people . . . thousands of people, who knows?" Laughter climbed in her throat, choking her, and turned to a coughing fit. Shaking fingers sought the water glass.

The Colonel entered. "Woe boy," he said. "Whew, 'nother day." He hung his jacket and braided cap, then settled into his stuffed swivel chair, and he glanced through the stack of memos that had been impaled on his desk pen. "Woe boy. 'Call General Fleeting for reverification of Pacific flash.' Awrightee. Woe boy. 'Nother day."

She returned the glass to the desk. "Have been looking into everyone's windows. Just for a fraction of a second-peering around-then vanishing. The police are very alarmed. They cornered one, but he got away. A skinny little fellow in rags, they say. Mongoloid features. Everyone who's seen one in his window says the face was Mongoloid. Some grocery stores have been looted in the same areas. It all started near the docks and is moving west. People from a ship, police think. Perhaps non-citizen types. The police are mobilizing."

It was just another story of city confusion-oddballs on the march-and yet 
Lish was surprised by the concern he felt, as if there was meaning in it for him alone.

"To think that the day after tomorrow is a holiday," Wendy continued, "and $h e$ is leading the parade. If I had my way he wouldn't even go out on the front porch with such crime in the streets."

Chester Bravo came in. "Morning Colonel. Morning Wendy. Hiya Lish. Boy, did you hear about those Peeping Toms? They must think they're some kind of nuts. Oh boy, another day. Another day, huh Lish?" Though his clothes were fresh, deep sprays of wrinkle shot from knee, crotch and elbow. Collar tips curled skyward. Heavy grey eyelids hung halfway between open and shut.

Bravo was Lish's friend. One night a week he'd go to Lish's place, or Lish would visit him, and they'd drink beer and talk. Bravo talked about laundries that lost his clothes, supermarket clerks who tried to deceive him and airlines that screwed him out of jet planes and into wing seats on turboprops. (He had flown to the Midlands and back three years ago, visiting his mother.)

For the most part, however, they didn't pay attention to what each other said during these meetings, and since they knew no one was listening, they didn't care what they said, and they got a lot off their chests that way. As for Lish, he usually caught onto one idea early, and when his turns came he repeated it, polishing and rearranging as the hours passed. By the end of the evening he was finally saying what he meant, or, just as often, discovered that what he had just said was worth believing. Most of the letters to his sons, letters about life, politics, brotherhood, got started that way.

He wasn't always preoccupied with such reasonable topics. One time he got it into his head that he had chosen to lead his life. God was pushing him to hurry and make up his mind, and so he chose this life. That made God mad, and He told Lish to show some spirit, but he wouldn't change it. The time before he had suffered a stroke at fifty-three, then prostatitis. Never did make senator. Dead and broke at sixty. The time before that he had been in chains half his life. And before that he had died of snake-bite, bayonet wounds, broken heart, leprosy, starvation, sunstroke . . . No thinks, buster; he'd take this life. God just shrugged and moved on to the next guy. Yes sir, Lish wanted this one-a little solitude, safety and comfort for a change. He could use the rest.

He had then asked Bravo if he could remember that far back, but Bravo wasn't paying attention. Lish guessed he couldn't really remember all that, though it had sure seemed like he could when he said it. When he paid attention, Bravo was just wrapping up his end of the discussion; "Put it this way: in the summertime I wish I was outside, and in the wintertime I'm glad I'm inside."

No matter what the weather was like, everyone in the basement assumed that it was cold and rainy. So they were pleasantly surprised to climb to the first floor and be greeted with sunshine. The Octagon is built around a park. In the park are trees and flowers from all over the world, and there are walks with benches, and in dead center there is a green and white snack bar whose gingerbready roof 
makes it look like an old-time band shelter. During coffee breaks Lish and Bravo would amble through the corridor that circled the park. Glass-covered portraits of generals, admirals and civilian administrators from earlier wars hung on the walls. Through the years the government portrait painters had remained faithful to the same deathly shade of pink for cheeks and foreheads and to the concept that behind every man there stands a stern, burnt umber backdrop. Tiny blocks of white glowed on every eye and lip. Lish had gotten to know each face. He believed that office moods were reflected by the faces that hung nearby, and thus he had become fond or fearful of offices he had never entered.

Because of its size, the building is always in need of repair. Walls crack, ceilings fall, pipes burst, and so troubleshooting squads of plasterers and plumbers are forever zooming through the halls on huge tricycles or electric carts. So attuned was Lish to the distant tinkling of their warning bells that the sound often awoke within him a sense of longing for other parts of the building similar to that for other parts of the world brought on by train whistles in the dead of night.

That particular morning he and Bravo circled the park twice. Troop commitments had increased in the Pacific, and the services were clamoring for larger input into such diverse courses as Swamp Boat Pilots School and Memorial Activities School. Of course, as is always the case in rapid buildups, they didn't have the men, and the Colonel was in a tizzy gathering figures with which to brief the generals. His chief aide on these rush projects was an athletic young GS six who, though neither intelligent nor experienced, was blessed with a talent for remembering figures. The Colonel would cock his pencil, then name a class and a month, and the young six would babble a stream of figures. While the Colonel scribbled and calculated, the six whistled, bouncing on his toes and pretending to dribble a basketball. Sometimes he hit upon a significant figure1492, for instance-and both of them would chuckle. Bravo would laugh out loud.

High pressure projects like that always upset the office. When Lish and Bravo returned from their walk, they found Wendy cleaning up after knocking over her glass. Later she kicked the adding machine cord from its socket, barked with laughter at some sudden memory, and fumbled with her huge class cards- arranging, rearranging, accomplishing nothing. Bravo was the only one who was not disturbed. Lish and he had the same job, and Lish would see him bent over his scroll, keeping steady pressure on the handle and singing to himself. As for Lish, he bided his time. Besides being put off balance by the office confusion, he was still bothered unaccountably by Wendy's story.

At five, when the workday ended, he dug in. The Colonel remained, compiling and editing. Finally, when lip smacking and foot tapping no longer irritated the margins of Lish's consciousness, he glanced at the Colonel's desk, saw it empty. Alone, he got his work done.

Catlin, L. C. Jr. . . . Catlin, W. W. . . . D's, E's. A heavy dose of clerk-typists and light vehicle drivers. Wasting Baptists and Catholics on flunky support jobs instead of putting them into combat arms where they belong. He was playing safe, afraid to make the commitment to danger. Airborne, ranger, demolition, 
night assassin-all the tough jobs went begging. Cowardly fingers and hot kidneys told him that he was scared. He felt his forehead; probably over 100. He got up to Haskill, P. H., but couldn't make himself put the boy in artillery, though that was all he was good for. He gave in again, made him a chaplain's assistant.

Though flesh colored themselves, the basement walls are lined with photos of sallow-cheeked soldiers in grey tones and black. Legs are plunged in slime, eyes lost in helmet shadow. Wet jungle leaves bleed onto ribbons of glistening cartridges, stained bandages and jaws that hang.

Down the hall the drawer of a file cabinet was slammed. An adding machine chattered.

First floor walls, lined with portraits, are green.

The plastic tip of a cigar jutted like a broken tusk from the Negro's mouth. He was a confident performer, spinning the wheel of his buffing machine with one pink palm. Lish knew that the man wanted him to get in the way or grumble an insult, but he remained close to trash containers and water coolers, saying nothing, so the Negro pretended he didn't exist. (Lish was frightened by the way Negro threes, fours and fives took over at night. They smoked mentholated cigars and wore tweed jackets with phony leather patches, and they sought insults from the likes of him.) The Negro's powder blue golf cap disappeared around the corner, and behind him stretched a glowingly buffed aisle. Lish followed it down the ramp toward the smell of fog.

Under fluorescent streetlights salamanders sprang from stacked cannon balls. They scooted up marble pillars and disappeared down barrels of stubby brass mortars. Boys and girls from the barracks struggled and gasped among the headstones of Soldiers' Cemetery while rats crawled over the boots of sleeping MPs. Heavy chains moaned in the breeze. Downtown, in steamy theaters, winos choked in their sleep while nude women with whips battled on the screen. Teenage Negroes decked out in khaki uniforms and white plastic Sam Browne belts gathered in surplus stores to fondle worn holsters and saw-toothed bayonets.

Lish knew the city and everyone in it. He had known them all from the first day in kindergarten when the smiling lady sat them in rows of hard chairs so that they had two invisible lines through them, one from chest to back, the other from shoulder to shoulder. She told them that they could never break from these lines. The room was large but they had to sit in the little square in the sunlight. There were toys on shelves, but the children could not go to them. Mothers lined the shadowed walls, coats buttoned to the chin, and like their children they were strangely scared so that looking at them through the floating chalk dust did not give the children comfort. Galaxies of chalk dust swirled lazily around and around within the slanting pyramid of sunlight. The smiling lady chanted monotonous sentences, and the children gripped the edges of their seats, waiting in the sunlight until the odors came and then the sobs. A boy in a corner, then the girl next to him, another boy two rows away. They were soiling themselves, yet still they clung to their chairs. Soon children in every row lost control, and they cried aloud. The moaning of their mothers set the children shivering, and two bolted, ran screaming into the shadows. To Lish's left vomit splattered, 
and more kids broke from their lines and ran. Still, the smiling lady's chanting could be heard above the wailing of banished children and shamed mothers. The survivors clung to their chairs as if they were the center of the universe, and to leave them would be to whirl forever away from the center, farther and farther into darkness. Lish's spirit reached out to float in the languorous peace and purity of the chalk dust.

Those who bolted never returned to the lines. Two from Lish's class were dead. Others would doubtless die in institutions. Still others had simply disappeared. (Find them in the putrid movie houses or sprawled in alleys, he thought.) As for himself and the rest of the class, they have maintained their precarious balance, though nothing is final, he knew, and the pressures were always there.

Through windows near his home Lish saw the daytime workers, white and black alike, locked in their apartments, preparing to tiptoe through another day, marking time and keeping clean.

He could not sleep but sat fully dressed in the center of his bed, waiting.

Keeping clean, that's what he hadn't done. The letters he had written had not been filled simply with idealism and poetry. All that he could not speak of to Bravo or Wendy he had spoken of to his sons. He had told them of the agency backbiting, of how Audit Central-a group of Jews, primarily-was trying to get sanctions to pry into the Employee Service Organization to investigate pension fund investments. Because they wanted to expose the organization and take control of it, they had chosen the exact moment when an ESO apartment building project had collapsed. He had told them of the office two doors from his own where hate burned in the air like acid fumes. There, an officer and a GS fifteen connived against a man across the hall who was dying of throat ulcers and could barely whisper-and then only to himself, as he had lost all his allies. He had told them about the Negroes and how they were learning everything about the building-the foundation, power sources, job operations. ("Too much knowledge for a bitter people," he had written.) He told them about the silent young Negro who each day pushed a cart stacked high with punch cards, each of which told something about someone, down all those corridors, past all those offices, and into a computer room where he worked alone. ("It makes me cringe to think of what he knows.") And he told them how he feared the President ("He is getting all the power because he has all the knowledge, but what if he is unwise, or corrupt or unwell? Even with him in office, much as he is loved, who knows what he is after? Who really knows?").

The letters often ran to fifteen or more numbered paragraphs, and all that he had written to sons he had never seen and had never heard from. Receiving and, hopefully, reading the letters was the price they and the foster parent organization paid for a sizable monthly check for him.

No, he was not clean, and memories of what he had written gnawed at him. He began to wish that the translators had botched the job, that all his meaning had been lost, that the letters were gibberish.

Sitting cross-legged at the dead center of his mattress, he inventoried his 
symptoms-burning kidneys, the shakes, a touch of vertigo. It was the vertigo that frightened him most, for it reminded him of what he wanted most to forget, that he could not stay forever safely within his lines, that his power to resist the forces outside the lines was slowly eroding, that no one could survive indefinitely in a war against time and nature. The impermanance, the lack of stability-that's what works on a man, he thought. The trouble with sickness is that I lose my sense of proportions, can't keep a grip on things. I just see what's crazy in the world which only makes me more sick. It's hard to keep your balance-that is, to stay healthy while remaining prepared to be ill. When you're sick you can plan on being that way, but once you're healthy again you get forgetful; suddenly you're knocked out again, seeing only what's out of control. It's hard to keep your balance, hard to perceive balance in the universe.

He sat in the darkened room feeling drops of sweat roll like cold stones over his ribs. There were screams in the distance. Whole city blocks went dark at once, and the screams grew louder as the seconds ticked by. Windows rattled as a helicopter hovered overhead. The beam of its searchlight slowly, evenly swept the buildings across the street, then swung up Lish's block until he was suddenly blinded by the fierce flood of white. The whole room shook. Flares were ignited in his brain which sputtered with cold fury long after the helicopter had moved away. Then the odors hit him, the gross rancid stink of deprived foreigners who had infiltrated his city and who, he knew, were seeking him.

At work next morning everyone was talking about the weird and frightening faces that had appeared briefly, inquisitively, at their windows. Dozens of supermarkets and clothing stores had been looted, and clerks who had tried to stop the looting were found with their heads chopped off. Stories were told of secret invasions, mass murders, etc., going on in the countryside around the city. In town, police had fired at several of the strangers, and gangs of teenagers had cornered others. But the little people had exhibited amazing guile and strength in fighting off attackers. In skirmishes throughout the city they had made good their escapes, even when greatly outnumbered. As yet none had been captured, dead or alive.

So unreasonably sure was Lish that the whirlwind was seeking him out that he could no longer resist, and he sat waiting to be found. Haskins, A. J. was the next name. Lish stared at it all day.

When the workday ended everyone stampeded for home, and Lish was left alone. He wandered the halls, feeling blue.

Featured in the display cases on third floor were Uniforms of Yesteryear, and Lish tried to interest himself in sabers and spurs and faded guidons, then, as he walked along, in giant murals of grenadiers storming a dusty red mountain at sunset, of cavalrymen on frothy stallions charging through fields of wheat at high noon, of tanks burrowing into a twilight winter forest and paratroops tumbling toward a lethal quiltwork of summer farms.

From far down the hall came a screech of tires, then a crash. Lish ran for the sounds. An electric ambulance soon overtook him, but he arrived in time to 
watch the attendants lift a wounded plumber into their vehicle. After the machine had screamed away, he leaned on the wall to catch his breath. A wheel from the overturned tricycle still looped round and round the floor in ever smaller circles. Finally it clattered and lay still. Plungers that had spilled from the wounded man's quiver were scattered for twenty yards behind the wreck. The distant siren screamed, and Lish, so abruptly alone again and unable to give aid, felt sad.

There was nothing else to see, nowhere else to go, no one left to talk to but black floor-buffers and trash collectors out for his blood. Sad was the word, all right; sad and helpless against whatever it could be that fate was luring him into. Go home, fate said. Your apostle from the dark side of the world is waiting. He went home.

It was just what he dreaded-the door open, a trail of blood, a figure sprawled on his bed. But he could never have anticipated the hot rush of father love that swept over him, caught in his throat, sparked tears, and set him in passionate motion for the rest of the night-washing blood from the boy's limbs, disinfecting wounds, prying jaws apart to pour in bouillon and honeyed tea. Easing the rusty blade of a pen knife from a calf, always more iodine. Pinching glass fragments from his scalp. Nourishment and quiet encouragement with which to battle fever and shock. Tweezers again, and reading glass to probe festered shoulder and thigh for shotgun pellets.

In the morning, as he ran out to buy clothes for the boy, he marvelled at the vigorous loving Lish he had discovered in himself last night. Back home he watched the boy struggle through a disintegrating net of fever, finally sitting, abruptly awake, and looking at him.

"Welcome," Lish said. "Welcome home, son."

Of course Wendy had them over to celebrate, poor envious woman, and invited poor envious Bravo. Exhausted by her labors, she sat next to her mother at the head of the table, her face as shiny as waxed linoleum but crisscrossed by wet ruts and gulleys, an eroded linoleum face, the eyes glass pellets in which floated the flame of a lone candle.

"Momma is so sad. They won't renew her license, so now she can't drive to the pool anymore. YOU CAN'T GO SWIMMING ANYMORE, MOTHER!"

The dusty old woman moved her gums, nodding over her plate. At the other end of the table Bravo was reading the paper. Between Lish and his son lay an immaculate, swollen turkey, its bronze skin gleaming like a surfer queen's belly. Steaming gravy, cranberry salad, sweet potatoes and mashed, spiced apples, ripe olives on a crystal platter. The table sparkled like a wedding.

"How old is he?" Bravo asked. "Looks between thirteen and thirty."

Only his son ate, squatting like a monkey, spoon flailing, neck and shoulders participating vigorously.

"Here's an interesting item," Bravo said. "Do you know how many people there'll be in twenty years? Take a guess."

Lish watched the bulging knobs of his son's jaw and felt sick. His stomach 
filled with oil and quicksilver. Like falling in a dream. I was wrong, he thought. They don't care and neither do I. (Where have you come from? How did you get here? What are you like?)

How terrible is the moment when you discover you have miscalculated. They are not joyful or envious. They mock and suffer. And what a messy alien he is, dripping gravy onto his shirt, not even caring. Oh, what a mistake.

He blew out the candle and tiptoed to the door.

Lish ended up in the park he used to visit as a child. The boy had long since caught up, and his greasy hand was clamped around Lish's fingers. "How do you use this?" he asked, pointing at a row of swings. His accent was already disappearing. "And that?" A rusted slide under a tree. Lish didn't want to talk to him, didn't want to hear him, didn't care. Instead, he wept deep within himself at the sight of his old swimming pool, now full of weeds and beer cans. Weeds had conquered the grounds, overflowing the walks, strangling and decapitating the water fountain. The stand where Lish used to buy licorice whips and Fudgesicles was boarded up, its tarpaper roof collapsed. That's what time does to you, Lish thought, and his lips began to quiver.

A blond cheerleader in a maroon letter sweater, her cheeks amazingly red in the leaden overcast, pedalled a racing bike round the walk that circled the pool. A younger sister sat on the handlebars, eyes squinched shut as drops of rain splashed her face. As the girls sped by, Lish scowled. You just wait, he thought. If you think you're so God damn young, you just wait a few years.

Suddenly the boy bounced up and down, gripping his crotch. "Oh, oh, can I ride it, pop?" He stared at a tattered carrousel at the edge of a woods. "Aw, please, can I? Are you mad, pop? Can I? Are you?"

"I don't give a damn," Lish said, and the boy bounded away. He leaped onto the ramp, crossed it to the machinery at the core, and he shook the sleeping attendant. Seconds later he was mounted on a white stallion, kicking its plaster flanks, while the machine creaked and clattered alive. Sounds of a calliope came from loudspeakers, and slowly the ramp revolved. Lish settled down on a bench under warring clouds, feeling rain water trickle down his neck. The girls had stopped to watch.

So this is how it is, he thought.

His son reached for the brass ring, missed.

My first son has come to me, and this is how it is.

He reached again, this time stretching beyond the ring to grab the wooden pole on which it was bracketed. The pole bent after him. A crack like a rifle shot, and the pole dragged free in the Mongol horseman's fist.

$\mathrm{I}$ am $\mathrm{X}$ years old, have $\mathrm{Y}$ years to live; I feel rain on my scalp, and my gritty stomach shivers; there is my son on a merry-go-round.

The attendant tripped through the weeds, running after the horse and waving his arms. Losing ground, he stopped and swung his wet face around to meet the onrushing stallion. The boy was crouched low over the horse's mane. He braced the pole under his arm. Thunder spilled through the black thicket of elms and 
evergreens, rattling fixtures under the gay circus canopy, and bloody hips arced for a moment above the rain beaten weeds. Quivering pole marked the spot. Calliope, thunder, and hissing rain; orchestration for the Mongol's victory solo. Hiyeeeeee!

All sweetly withered and coiled with cramps of melancholy, Lish watched the girls speed away through the steely downpour, and he smiled.

He vaulted a split rail fence and ambled along the bank of a highway near fields of standing grain. Fumes from the hot asphalt cleared his head, and the sun burned illness from his flesh. Recuperating on a sunny afternoon, mildly feverish but pulse strong and stomach growling, Lish moved slowly, still a bit bent, thinking about food. A chocolate malted milk in a white-tiled, frigid malt shop served by chocolate hands from a frosty, stainless steel blender. Spudnuts, Twinkies, Sno-Balls, dime fruit pies in glazed envelopes, Korn-Kurls, Fritos, pressure packed Piggy-Snax-crisp clean wrappers and crunchy, sweet dry punishment for an empty stomach. Stuff it full, wedge in the fluff and crispness, the sanitized aluminoid decay retardants, and watch the pile of wrappers grow on the tile floor, hand gripping wet wax container of chocolate malted. It was a clean vision, sweet and guiltless, and as he entered the box shaped shadows where city and farm fields merged, he searched for such a shop, but he was hemmed in by a mass of bodies in wet cotton, faces like boiled crabmeat. Tiny hands gripped the stems of tiny flags, and everyone squinted in the direction Lish had just come from, their vision skipping over distant shimmering pools in the asphalt to a shiny pin-point that slowly grew toward them. The parade! $\mathrm{He}$ was coming! Lish nearly tripped over a curly headed child in a harness. Its face wrinkled, steamy wet with discomfort, and the mother reeled in the harness and lifted the child to a sunburned shoulder without once turning her sun-glasses from the point of light. The greater Lish's friction against the hot crowd, the more desperate his hunger grew. He hugged shop windows and brick walls, peering through each screen door and praying for a lunch counter. For now, a warm Nehi orange would do just fine-plus maybe a melting caramel sundae.

Cameras were unlimbered from leather cases, light meters consulted. A pair of motorcycle policemen glided by, their sun goggles sparkling with crescent shaped reflections of office windows. Then Lish saw his son's excited eyes bobbing in the crowd. Lish crouched low, snaking between moist beltlines. He spied a lime popsicle in a kid's hand, grabbed the stick and lunged from the shocked face, losing himself before the alarm could be sounded. It was like a mouthful of coals. Pellets of heat shot through his fillings to burn in his brain, and suddenly . . . thump, thump-a migraine. Out of the shadows and into a gully, and he backed up a grassy slope, reaching for the pain. His son was closing fast; " $\mathrm{He}$ is passing, father. You must get down. Get down!" Beams of sunlight poked at Lish from white helmets and the fenders of floating limousines. The crowd yelled, waving flags.

The boy tackled him, and when, from above-behind-somewhere, the gun 
sounded, Lish lifted his head to see a world of open mouths. The limousines streaked over the bridge, bodies lay flat all around him.

He paused at a storewindow where on a dozen television screens the mouth of the land's most beloved newscaster worked at a frantic tempo.

He fled into an alley, his son following. The wail of sirens echoed among the walls. Lish moved faster, yet the boy remained at his heels, breathing furiously. When they were safely out of view the boy shoved him into a cluster of garbage cans, pinning him against a dirty wall with one hand and thrusting the other under Lish's face. "Look," he said. In his palm lay a strangely tapered cartridge case. An ancient and gaudy piece, it looked as lethal as a bannister ornament.

"No, no, that's not it," Lish said. "Can't be. Get away."

The boy leaned closer. "We could take them now," he whispered.

"Take them?" Lish's head was about to explode, yet he was so weak that he was ready to surrender-give in to anything. "Take who?"

A policeman appeared not fifteen yards away, the barrel of his revolver leveled at their midsections. For one frozen second he looked at them, they at him. "He did it!" Lish screamed. "Look in his hand!" And he ran, heard two explosions from behind, turned the corner and mingled with the glassy-eyed crowd.

His fingers worked at his throbbing temples.

Back, back to the quiet countryside, away from flesh and evidence. Corn stalks snagged his shirt. Dust and pollen turned to paste on his tongue, and in his head marbles of pain, replicas of the shimmering ball of sun, rammed one another and exploded, pouring fire onto new universes and locking old ones into frigid darkness. Eternal motion, eternal pain, all useless. Oh for just a canteen full of warm Kool-Aid!

While the soles of his feet burned on the hot earth, his belly was chilled by twilight breezes.

He moved across a dusty tractor trail, over a fallen barbed wire fence and into the forest, lured by darkness and the perfume of ferns. The pine needle carpet was cool underfoot, the air still, almost cold. Cautiously he threaded his way between maple saplings and clumps of poplars, moving toward the sound of water. I'll drink and relax for a minute, he thought, and then I must find my way home-cover the window, bolt the door-if only I can find my way from here. A cuticle of moon glowed beyond jagged branches. Home. It was so far away, and he was so tired. It was all very sad, he decided, kneeling at the edge of the stream.

He had raised his head to belch, contemplating cool heavy stomach and icy teeth, when he became aware of the strange situation of his hands. While the left sank gradually deeper into sand and decayed leaves, the right rested upon matter that was smooth and solid. Cautious fingers discovered a buttplate of steel, and he hauled a rifle into his lap. The stock was scarred and crudely finished, the receiver a clumsy pod of stamped steel. It was a middle-European sweatshop rifle. He imagined that the man who had milled the stubby bolt and the man who had worked it in action, both ignorant gnawers of black bread- 
peasants with mean cheekbones and rancid whiskers-could be uncovered with their children in a mass grave somewhere in a forest like this one.

The gun had not been away from a man's care for long, however, as the bolt moved easily, flipping to the pine needles at his knee a cartridge case of horribly familiar design.

He backed away from it as if from a sleeping snake. He flung the rifle into the brush. In an instant he was on his feet, charging along the edge of the stream. He was being watched. They were out there among the trees, and they were watching him. He just knew it. 